\title{
Virus Production by Abelson Murine Leukemia Virus-Transformed Lymphoid Cells
}

\author{
ANTHONY SHIELDS, ${ }^{1}$ NAOMI ROSENBERG, ${ }^{2}$ AND DAVID BALTIMORE ${ }^{1}$ * \\ Department of Biology and Center for Cancer Research, Massachusetts Institute of Technology, Cambridge, \\ Massachusetts 02139, ${ }^{1}$ and Department of Pathology and Center for Cancer Research, Tufts University \\ School of Medicine, Boston, Massachusetts $02111^{2}$
}

Received for publication 5 March 1979

\begin{abstract}
Cell lines obtained by in vitro transformation of bone marrow with Abelson murine leukemia virus (A-MuLV) can be divided into three classes: producers, releasing reverse transcriptase-containing particles and infectious virus; nonproducers, releasing no viral particles; and defective producers, the most common phenotype, releasing particulate reverse transcriptase in the absence of infectious virus. When such cell lines were analyzed 1 to 2 weeks after their isolation, however, all produced infectious virus. Because these cell lines were carried in culture, many ceased to release infectious virus but produced defective virions. One defective producer, SWR4, has been extensively studied. The particles it produces have the same density as that of virions of Moloney murine leukemia virus (M-MuLV). The particles contain no 35 to 70S RNA, as determined by analysis of $\left[{ }^{3} \mathrm{H}\right]$ uridine-labeled particles, and exhibit no endogenous reverse transcriptase activity. Although the reverse transcriptase enzyme is of normal size, the major structural protein of the defective virions has a molecular weight of 28,000 (p28), in contrast to the p30 of M-MuLV, and no viral glycoprotein was evident. The defective particles do not appear to arise either from the helper virus or from Abelson virus. An alteration of the protein of the helper virus is an unlikely source of $\mathrm{p} 28$ because particles produced by lymphoid cells transformed with another strain of M-MuLV as helper (M-MuLV-TB) contained p28 with an unaltered cleavage pattern, although M-MuLV-TB p30 differs from M-MuLV p30. The A-MuLV genome lacks tha capacity to code for the reverse transcriptase and p28 of the defective virions and therefore cannot be the source of the defective virions. Clones of fibroblasts infected with A-MuLV only occasionally produce defective particles. The defective particles therefore probably arose from an endogenous virus that is preferentially expressed in the class of lymphoid cells transformed by A-MuLV. This interpretation implies that the majority of AMuLV-transformed lymphoid cells completely lose expression of the helper virus genome.
\end{abstract}

Abelson murine leukemia virus (A-MuLV) is a defective retrovirus that causes a rapidly progressive lymphosarcoma in mice and will induce growth of transformed lymphoid cells after in vitro infection of mouse bone marrow cells (21). At least some A-MuLV-induced lymphoid cell lines appear to be related to cells of the Blymphocyte lineage because they contain immunoglobulin-related polypeptides $(18,19,27$, $28,29,33)$.

All A-MuLV-transformed cell lines, producer or nonproducer, contain a protein of molecular weight 120,000 that is made under the direction of the A-MuLV genome $(20,35)$. This is the only A-MuLV-specific protein that has been identified. Like the murine sarcoma viruses, A-MuLV needs a helper virus to provide its virion structural proteins.

A-MuLV is also capable of transforming fibroblastic cell lines in vitro (25). Transformed fibroblastic and lymphoid cell lines that make no functional helper virus have been isolated, and A-MuLV can be rescued from such lines by superinfection with a competent helper virus. Stocks of A-MuLV can be made with a variety of helper viruses by superinfecting nonproducer transformed cells with different competent murine retroviruses. Although any helper virus can provide the functions necessary to allow AMuLV to transform fibroblasts, the ability of the virus to transform lymphoid cells is correlated with the oncogenicity of the helper virus (22, 
24). A-MuLV stocks made with helper viruses of low oncogenicity are unable to cause Abelson disease in mice or to transform lymphoid cells. Certain helper viruses are also unable to establish a stable infection when used to superinfect A-MuLV-transformed lymphoid cell lines (22). Even lymphoid cells producing highly oncogenic helper viruses have been found to cease virus production after being carried in culture for several months (35).

Although the question has not been directly investigated previously, our experience with fibroblastic cells that are infected with A-MuLV has been that stable producers and nonproducers result. The instability of helper virus production seen with lymphoid cells has not been evident. Furthermore, when fibroblastic cells are infected with Moloney murine leukemia virus (M-MuLV), a representative effective helper virus, stable producers, and defective producers result (26). The defective producers appear to arise from infection with a variety of mutant proviruses giving rise to a variety of stable phenotypes.

The disparity between the apparently stable fibroblast-M-MuLV relationship and the apparently unstable relationship between A-MuLVtransformed lymphoid cells and helper viruses led us to undertake a systematic investigation of virus production by $\mathrm{A}-\mathrm{MuLV}$-transformed cells. We report here that most $\mathrm{A}-\mathrm{MuLV}$-transformed lymphoid cells evolve to a state where no helper virus production is evident but where the cells make a highly defective particle that probably arises from an endogenous provirus in the original target cell.

\section{MATERIALS AND METHODS}

Cells. NIH/3T3, BALB/3T3, SC-1, XC, and FG-10 cells were grown in Dulbecco modified Eagle medium supplemented with $10 \%$ calf serum (Microbiological Associates). Transformed lymphoid cell lines were derived from individual foci of $\mathrm{A}-\mathrm{MuLV}$-infected bone marrow cells and adapted to growth in RPMI-1640 medium supplemented with $10 \%$ heat-inactivated fetal calf serum and $50 \mu \mathrm{M}$ 2-mercaptoethanol (Kodak Chemical Co.) (22). SWR4 was derived from an SWR/ $\mathrm{J}$ mouse; 242, TB-11, and TB8-5 were derived from NIH/Swiss mice; 18-4 was from a BALB/cJ mouse; and BR48 was from a C57BR/cdJ mouse. Superinfected cell lines are designated /M-MuLV.

The series of transformed fibroblasts was derived by infecting NIH/3T3 cells at an approximate multiplicity of infection (MOI) of 0.025 focus-forming unit (FFU) and 0.05 plaque-forming unit (PFU) per cell. After a 1.5-h adsorption period, the cells were washed and trypsinized, mixed with agar-containing medium, and plated in a final concentration of $0.3 \%$ agar at $10^{3}$ to $10^{4}$ cells per $10-\mathrm{cm}$ plate. After 17 days at $38^{\circ} \mathrm{C}$, transformed colonies were visible by eye and were picked by using a Pasteur pipette. They were trans- ferred to $60-\mathrm{mm}$ dishes and grown up and tested for release of reverse transcriptase activity and virus by $\mathrm{XC}$ and focus assays.

Viruses. A-MuLV stocks were routinely prepared from an NIH/3T3-derived, A-MuLV-transformed cell line, ANN-1 (25), rescued with M-MuLV-1 (6). A second, clonally derived fibroblast nonproducer cell line, A2, was made by infecting NIH/3T3 cells with AMuLV(M-MuLV-1) at an MOI of 0.005 FFU and 0.01 PFU per cell and cloning in agar as described above for NIH/3T3 cells infected with A-MuLV. Of the 13 clones isolated, A2 is 1 of 3 that did not release infectious virus. M-MuLV-TB (a gift of P. Wong, University of Illinois) was used to rescue A-MuLV from A2 cells by infecting them at an MOI of 0.5 . After adsorption, cells were trypsinized and plated in microtiter wells at approximately 0.2 cell per well. After 15 days, clones were transferred to dishes. Of the 11 clones tested, only 1 produced virus.

In all cases, virus stocks were prepared from exponentially growing cells. Culture fluids were centrifuged at low speed and filtered through $0.45-\mu \mathrm{m}$ filters (Millipore Corp.) before use. A-MuLV and M-MuLV were titrated by the standard fibroblast transformation assay for A-MuLV (25) and the XC (23) or the S+Lplaque assay (2) for M-MuLV. All infectivity assays were done in the presence of $8 \mu \mathrm{g}$ of polybrene (Aldrich Chemical Co.) per ml.

Reverse transcriptase assay. Exogenous reverse transcriptase assays were performed as described by Rosenberg and Baltimore (22) by using polyriboadenylate and oligodeoxythymidylate. Virus used to determine the ratio of endogenous to exogenous activity was collected by centrifugation, purified by banding in a density sucrose gradient, centrifuged, and suspended in $0.5 \mathrm{ml}$ of $20 \mathrm{mM}$ Tris (pH 8.3). The endogenous assay was carried out at $37^{\circ} \mathrm{C}$ in a $0.1-\mathrm{ml}$ reaction mixture containing $60 \mathrm{mM}$ Tris (pH 8.3), $60 \mathrm{mM} \mathrm{NaCl}$, $6 \mathrm{mM} \mathrm{Mg}$ acetate, $20 \mathrm{mM}$ dithiothreitol, $1 \mathrm{mM}$ dATP, $1 \mathrm{mM}$ dCTP, $1 \mathrm{mM}$ dGTP, and $100 \mu \mathrm{Ci}$ of $\left[{ }^{3} \mathrm{H}\right] \mathrm{dTTP}$ $(40 \mathrm{Ci} / \mathrm{mmol})$. Duplicate test tubes were removed at $1,2.5$, and $5 \mathrm{~h}$ and stored on ice before precipitation with trichloroacetic acid. The reaction rate was determined by linear regression analysis.

Analysis of virion density and RNA. Approximately $10^{9}$ exponentially growing lymphoid cells were labeled with $10 \mu \mathrm{Ci}$ of $\left[{ }^{3} \mathrm{H}\right]$ uridine per $\mathrm{ml}$ for $3 \mathrm{~h}$ at $10^{7}$ cells per $\mathrm{ml}$, followed by the addition of two volumes of normal medium. After an additional $4 \mathrm{~h}$, supernatants were harvested and clarified, and the virus was collected by centrifugation. The virus was resuspended, sonicated, and layered on a 25 to $45 \%$ sucrose gradient in $50 \mathrm{mM}$ Tris (pH 7.5)-100 mM NaCl-1 mM EDTA. The gradient was centrifuged at $35,000 \mathrm{rpm}$ for 12 to $18 \mathrm{~h}$ at $4^{\circ} \mathrm{C}$. Fractions of $0.5 \mathrm{ml}$ were collected and assayed as described above.

The analysis of virion RNA was done on labeled virions produced and purified as described above. The virus from the gradient was lysed in $2 \%$ sodium dodecyl sulfate (SDS), and the RNA was purified by phenolchloroform extraction and ethanol precipitation. RNA was analyzed by sucrose gradient centrifugation by the method of Kerr et al. (10).

Protein analysis. Virions were purified by sucrose gradient as described above and suspended in $20 \mathrm{mM}$ 
Tris ( $\mathrm{pH}$ 8.3). They were lysed by the addition of NP. 40 (final concentration, $1 \%$ ) and heated at $67^{\circ} \mathrm{C}$ for 5 min. Iodination was performed by using lactoperoxidase (17) or chloramine $T$ (8). Immunoprecipitation was performed by using sera shown to be specific for M-MuLV p30 and gp70 (16) by techniques described in detail elsewhere (34). Briefly, labeled virus was precleared with normal serum and Staphlycoccus aureus Cowan strain 1 (11). Immunoprecipitates were then made by incubating the supernatants with $5 \mu$ l of serum and then collecting antigen-antibody complexes with $S$. aureus. SDS-polyacrylamide gel electrophoresis was performed on the discontinuous stacking system of Laemmli (12). Gels were stained with $0.025 \%$ Coomassie blue-10\% acetic acid (vol/vol)-25\% isopropanol (vol/vol) and then destained in $10 \%$ acetic acid. After drying, autoradiography was done using Kodak No-Screen film.

Peptide digest analysis was performed by the method of Cleveland et al. (4), except that dried gels were used. After cutting out the band from the dried gel, the piece was rehydrated in $10 \mathrm{ml}$ of a solution containing $0.125 \mathrm{M}$ Tris ( $\mathrm{pH} 6.8$ ), $0.1 \% \mathrm{SDS}$, and 1 mM EDTA. This solution was changed four times over $1 \mathrm{~h}$. The gel slice was then placed on a new gel, and $10 \mu \mathrm{l}$ containing either $100 \mu \mathrm{g}$ of $S$. aureus protease, $100 \mu \mathrm{g}$ of papain, or $1 \mu \mathrm{g}$ of pronase per $\mathrm{ml}$ was added to the indicated slots. After electrophoresis, the gel was stained and dried and autoradiography was performed.

\section{RESULTS}

Virus production by A-MuLV-transformed lymphoid cells. A-MuLV-transformed bone marrow cells arising as single foci in the agarose transformation assay (21) were adapted to growth in liquid medium and tested for virus production using both infectivity and reverse transcriptase assays (Table 1). Three classes of cell lines were found: producers (e.g., 18-4), cell lines producing large amounts of particulate reverse transcriptase and high titers of infectious and transforming virus; nonproducers (e.g., BR48), cell lines releasing no reverse transcriptase or infectious virus; and defective producers (e.g., SWR4 and 242), cell lines releasing particulate reverse transcriptase in the absence of detectable plaque-forming or focus-forming virus. The $\mathrm{A}-\mathrm{MuLV}$ genome was present in nonproducer and defective producer cell lines because it could be rescued from them by the addition of a helper virus such as M-MuLV (Table 1). A-MuLV stocks prepared after rescue were indistinguishable by in vivo and in vitro infectivity assays from A-MuLV released by producer cell lines such as 18-4.

Cocultivation studies with the defective producers, 242 and SWR4, were carried out to determine if any infectious virus could be detected (Table 2). The lymphoid cell lines were treated with mitomycin C and cultivated with NIH/3T3, BALB/3T3, and SC-1 cells for the detection of ecotropic virus and CCL64 (mink lung cells) for the detection of xenotropic virus. The indicator cells were then carried as exponentially growing cultures for 3 to 6 weeks and assayed for reverse transcriptase production. No infectious ecotropic or xenotropic virus was recovered from SWR4 or 242 in these tests. No infectious virus

TABLE 1. Characteristics of A-MuLV-transformed lymphoid cell lines

\begin{tabular}{|c|c|c|c|c|c|c|}
\hline \multirow[b]{2}{*}{ Cell line ${ }^{a}$} & \multirow{2}{*}{$\begin{array}{c}\text { Supernatant } \\
\text { reverse tran- } \\
\text { scriptase ac- } \\
\text { tivity }{ }^{b} \\
\left(\mathrm{cpm} \times 10^{-3} /\right. \\
10^{6} \text { cells) }\end{array}$} & \multirow{2}{*}{$\begin{array}{l}\text { PFU re- } \\
\text { leased }^{c} \\
\left(\times 10^{-3}\right)\end{array}$} & \multirow{2}{*}{$\begin{array}{l}\text { FFU re- } \\
\text { leased }^{c} \\
\left(\times 10^{-3}\right)\end{array}$} & \multirow{2}{*}{$\begin{array}{c}\text { Lymphoid } \\
\text { foci } / 10^{5} \mathrm{FFU}^{d}\end{array}$} & \multicolumn{2}{|c|}{$\begin{array}{c}\text { Induction of Abelson dis- } \\
\text { ease }^{e}\end{array}$} \\
\hline & & & & & Incidence & $\begin{array}{l}\text { Mean la- } \\
\text { tent period } \\
\text { (days) }\end{array}$ \\
\hline $18-4$ & 240 & 14 & 7 & 570 & $6 / 6$ & 22 \\
\hline BR48 & 0.3 & 0 & 0 & $\mathbf{N D}^{f}$ & ND & \\
\hline BR48/M-MuLV & 55 & 6 & 5 & 60 & $8 / 8$ & 24 \\
\hline SWR4 & 23 & 0 & 0 & ND & $0 / 9$ & \\
\hline SWR4/M-MuLV & 300 & 80 & 20 & 33 & $3 / 3$ & 21 \\
\hline 242 & 2 & 0 & 0 & ND & ND & \\
\hline 242/M-MuLV & 62 & 5 & 2 & 1,000 & $5 / 7$ & 42 \\
\hline
\end{tabular}

${ }^{a}$ Lymphoid cell lines were derived by the in vitro transformation assay (21) and those designated /M-MuLV had been superinfected with the indicated virus.

${ }^{b}$ Reverse transcriptase assays were performed by using an oligo(dT) primer and poly(rA) template as described in Materials and Methods. Values of less than $500 \mathrm{cpm}$ were considered to be background.

c Plaque-forming units of M-MuLV were determined by the XC plaque assay (23). Focus-forming units of AMuLV were determined by the fibroblast transformation assay of Scher and Siegler (25).

${ }^{d}$ The efficiency of virus stocks to transform bone marrow cells was determined by using NIH/Swiss bone marrow (21).

e In vivo inoculations were done intraperitoneally in neonatal NIH/Swiss mice using filtered reverse transcriptase-positive supernatants. All mice were observed for 5 to 6 months.

$f$ ND, Not determined. 
TABLE 2. Release of infectious virus by defective producer lymphoid cells ${ }^{a}$

\begin{tabular}{lcccc}
\hline \multirow{2}{*}{ Cell line } & \multicolumn{4}{c}{ Cocultivated with: $^{b}$} \\
\cline { 2 - 5 } & NIH/ & BALB/ & SC-1 & CCL64 \\
\hline 3T2 & 0.6 & 0.4 & 0.4 & 0.3 \\
SWR4 & 0.7 & 0.4 & 0.2 & 0.3 \\
SWR4/M-MuLV & 114 & 28 & 140 & 0.4 \\
\hline
\end{tabular}

${ }^{a} 1 \times 10^{6}$ lymphoid cells were treated with $25 \mu \mathrm{g}$ of mitomycin $\mathbf{C}$ for $30 \mathrm{~min}$ and mixed with adherent cells at a ratio of $3: 1$. After $48 \mathrm{~h}$, the monolayers were washed, and adherent cells were maintained as exponentially growing cultures. Reverse transcriptase activity in the culture fluids was determined 3 weeks after cocultivation. Negative cultures were continued and retested 6 weeks after cocultivation.

${ }^{b}$ Values were obtained from the reverse transcriptase assay and are expressed as counts per minute $x$ $10^{-3}$. Values less than 0.7 were considered negative.

was recovered from SWR4 even after treatment with iododeoxyuridine (3) and cocultivation with indicator cells (data not shown), but infectious ecotropic virus produced by SWR4 superinfected with M-MuLV (SWR4/M-MuLV) was readily detectable (Table 2 ).

The proportion of cell lines with the defective producer phenotype was very high when randomly isolated cell lines were obtained from various mouse strains including NIH/Swiss, SWR/J, BALB/cAN, C57L/J, and C57BL/6J. To systematically determine the frequency of defective producers, several series of lymphoid clones from individual experiments were isolated and monitored for reverse transcriptase and infectious virus production after various times (Table 3). In experiments 1 and 2 , clones were adapted to liquid medium, a procedure that takes 3 to 6 weeks once the foci are removed from agarose. Most clones in these experiments were defective producers. In experiment 3 , cell lines were tested during their adaptation to continuous culture. One to two weeks after removing the cells from agarose, $57 \%$ of the focal isolates produced large amounts of virus $\left(>10^{3}\right.$ PFU per $10^{6}$ cells). After 1 month in liquid medium, the majority of cultures still released virus, but the amount of virus produced by the cells had decreased and some cell lines now displayed the defective phenotype. After 2 months in vitro (data not shown), three cultures classified at 1 month as low producers were retested and had become defective producers. One cell line classified at 1 month as a high producer was retested at 2 months and was stable, as were two cell lines designated as defective producers.

The interaction of M-MuLV with A-MuLV- transformed lymphoid cells differs from its interaction with fibroblasts in two ways. First, the interaction of $\mathrm{M}-\mathrm{MuLV}$ with fibroblasts is a stable one. As mentioned previously, subclones of M-MuLV-infected fibroblasts are all virus producers (26). In a variety of situations we have examined previously cloned, infected fibroblasts for loss of virus production and have not observed such loss. Second, transformation of fibroblasts with A-MuLV and M-MuLV helper generated a different pattern of phenotypes from that seen in lymphoid transformants (Table 4). Mainly producer or nonproducer cells were formed and the one defective producer in Table 4 may represent a spontaneous mutation because such mutant M-MuLV is often produced (26).

Characterization of the defective virions. One defective producer line was chosen for intensive study because it produced more defective particles than the others. This line, SWR4, released sedimentable particles containing reverse transcriptase (Table 1). To determine if the particles were virion-like, SWR4 cells were labeled with $\left[{ }^{3} \mathrm{H}\right]$ uridine and the labeled, re-

TABLE 3. Phenotypes of lymphoid cell lines

\begin{tabular}{|c|c|c|c|c|}
\hline \multirow{3}{*}{ Phenotype $^{a}$} & \multicolumn{4}{|c|}{$\begin{array}{c}\text { Expt no. } \\
\text { (time of assay) }\end{array}$} \\
\hline & \multirow{2}{*}{$\begin{array}{c}1 \\
(1-2 \\
\text { mo. })\end{array}$} & \multirow{2}{*}{$\begin{array}{c}2 \\
(1-2 \\
\text { mo. })\end{array}$} & \multicolumn{2}{|c|}{3} \\
\hline & & & $\begin{array}{c}1-2 \\
\text { weeks }\end{array}$ & $1 \mathrm{mo}$ \\
\hline High producers & $8^{b}$ & 25 & 57 & 21.5 \\
\hline Low producers & 0 & 12.5 & 43 & 57 \\
\hline $\begin{array}{l}\text { Defective } \\
\text { producers }\end{array}$ & 77 & 62.5 & 0 & 21.5 \\
\hline Nonproducers & 15 & 0 & 0 & 0 \\
\hline $\begin{array}{l}\text { Total number of } \\
\text { clones assayed }\end{array}$ & 13 & 8 & & \\
\hline
\end{tabular}

${ }^{a}$ Transformed lymphoid cell lines were derived by infection of NIH/Swiss bone marrow with A-MuLV. After a 1.5-h adsorption period, cells were plated in agarose-containing medium, and after 10 to 11 days, individual foci were picked and grown in liquid medium for the times indicated above before testing. High producers were cell lines producing more than $10^{3} \mathrm{PFU} / 10^{6}$ cells, as assayed using the FG-10 S+Lassay, and having reverse transcriptase levels greater than $10,000 \mathrm{cpm} / 10^{6}$ cells. Low producers released less than $10^{3} \mathrm{PFU} / 10^{6}$ cells (with most cell lines in this category releasing less than $100 \mathrm{PFU} / 10^{6}$ ) and had more than $500 \mathrm{cpm}$ in the reverse transcriptase assay. Defective producers released no PFU or FFU and had greater than $500 \mathrm{cpm}$ in the reverse transcriptase assay. Nonproducers released no PFU or FFU and had less than $500 \mathrm{cpm}$ in the reverse transcriptase assay; less than $500 \mathrm{cpm}$ is background.

${ }^{b}$ Values represent percentage of clones in that category except for the last line of data. 
TABLE 4. Phenotypes of fibroblast clones transformed by $A-M u L V^{a}$

\begin{tabular}{lcc}
\hline Class & $\begin{array}{c}\text { No. of } \\
\text { clones in } \\
\text { category }\end{array}$ & $\begin{array}{c}\text { Reverse transcrip- } \\
\text { tase assay } \\
\left(\mathrm{cpm} \times 10^{-3}\right)\end{array}$ \\
\hline Normal producers & 10 & $100-400$ \\
Nonproducers & 6 & $<0.5$ \\
Defective producers & 1 & 1.5 \\
Total number tested & 17 & \\
\hline
\end{tabular}

${ }^{a}$ Clones were isolated after infection of NIH/3T3 cells with A-MuLV(M-MuLV) and selection in agar as described in Materials and Methods. Clones were passaged for 2 weeks before testing. After overnight incubation, supernatants were harvested from subconfluent $10-\mathrm{cm}$ plates and analyzed by XC and focus assay. Producers are defined as releasing infectious virus detectable in both assays, whereas nonproducers and defective producers have no activity in either.

${ }^{b}$ Before analysis by reverse transcriptase assay (22) supernatants were concentrated 10 -fold by centrifugation. Backgrounds were not subtracted; values of less than $500 \mathrm{cpm}$ were not significantly above background.

leased particles were sedimented to equilibrium in a 25 to $45 \%$ sucrose gradient (Fig. 1). M-MuLV labeled with ${ }^{32} \mathrm{P}$ was used as an internal standard, and the particles from the superinfected producer lymphoid line, SWR4/M-MuLV, were analyzed in parallel. The defective producer released ${ }^{3} \mathrm{H}$-labeled particles containing reverse transcriptase activity that were of the same density as M-MuLV and the infectious virions of SWR4/M-MuLV.

To study their morphology, SWR4 and 18-4 particles were isolated, negatively stained, and examined by electron microscopy (Fig. 2). Although both preparations contained type $\mathrm{C}$ particles, the 18-4 particles had readily evident spikes characteristic of glycoprotein, but the SWR4 particles lacked such spikes.

To examine the RNA content of these particles, $\left[{ }^{3} \mathrm{H}\right]$ uridine-labeled RNA was extracted from the purified particles and displayed on a 15 to $30 \%$ sucrose gradient (Fig. 3). The producer, 18-4, released particles having RNA that sedimented at 70S as well as low-molecular-weight RNA, presumably mainly tRNA, that remained near the top of the gradient. The particles from SWR4 cells contained no demonstrable largemolecular-weight RNA, although it did contain some low-molecular-weight RNA.

As an alternative method of studying the RNA of the particles, we compared exogenous reverse transcriptase activity to endogenous activity in defective and nondefective particles. In the exogenous assay, oligodeoxythymidylate primer and polyriboadenylate template were added to the reaction mix to quantitate enzymatic activ- ity. The endogenous assay relied on the virions to supply 70 Senomic RNA and tRNA, the natural template and primer. The ratio of endogenous to exogenous activity should be a measure of the relative content of genomic RNA. SWR4 particles contained only 4 to $10 \%$ of the endogenous activity in particles from the normal producer, 18-4 (Table 5). This result confirms the lack of high-molecular-weight RNA in defective virions.

Proteins of defective virions. To examine the size of the reverse transcriptase contained in defective and standard virus, purified virions were lysed with NP-40 and their proteins were fractionated by centrifugation through 5 to $20 \%$ glycerol gradients. Assay of the fractions revealed no significant difference in size between

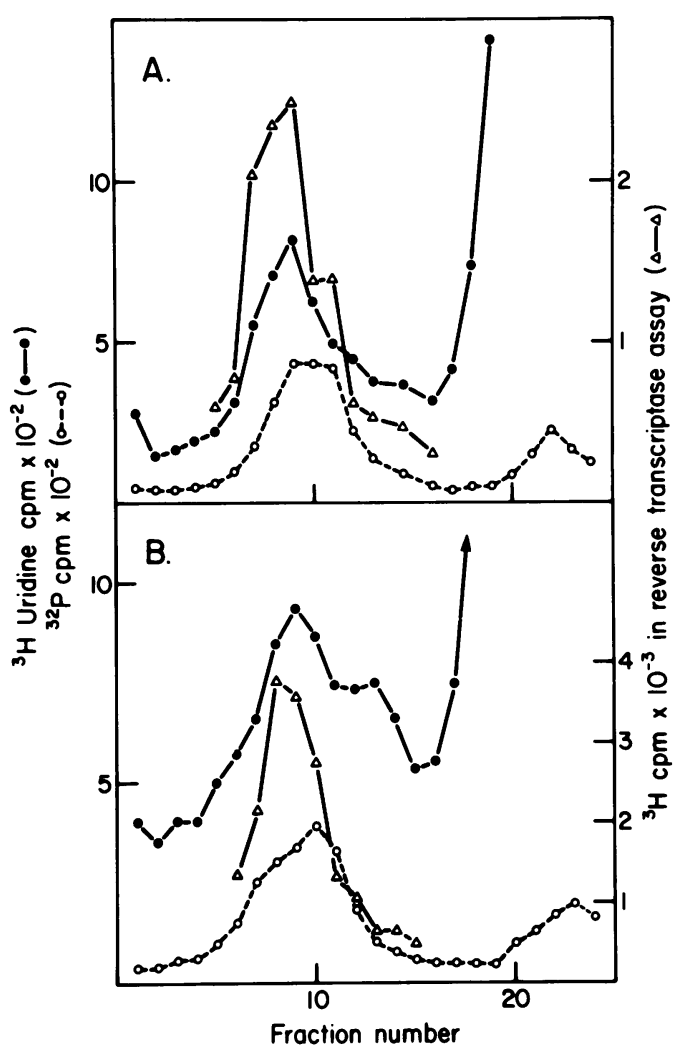

Fig. 1. Isopycnic sedimentation of normal and defective virions on sucrose gradients. [ ${ }^{3}$ H] uridine-labeled virions were prepared and sedimented on 25 to 45\% sucrose gradients as described in Materials and Methods. Portions of each fraction were assayed for reverse transcriptase activity or counted directly to determine $\left[{ }^{3} H\right]$ uridine. ${ }^{32} P$-labeled $M-M u L V$ was included in each gradient as an internal standard. (A) Virions from SWR4/M-MuLV, a cell line releasing infectious virus. (B) Defective virions from SWR4. 

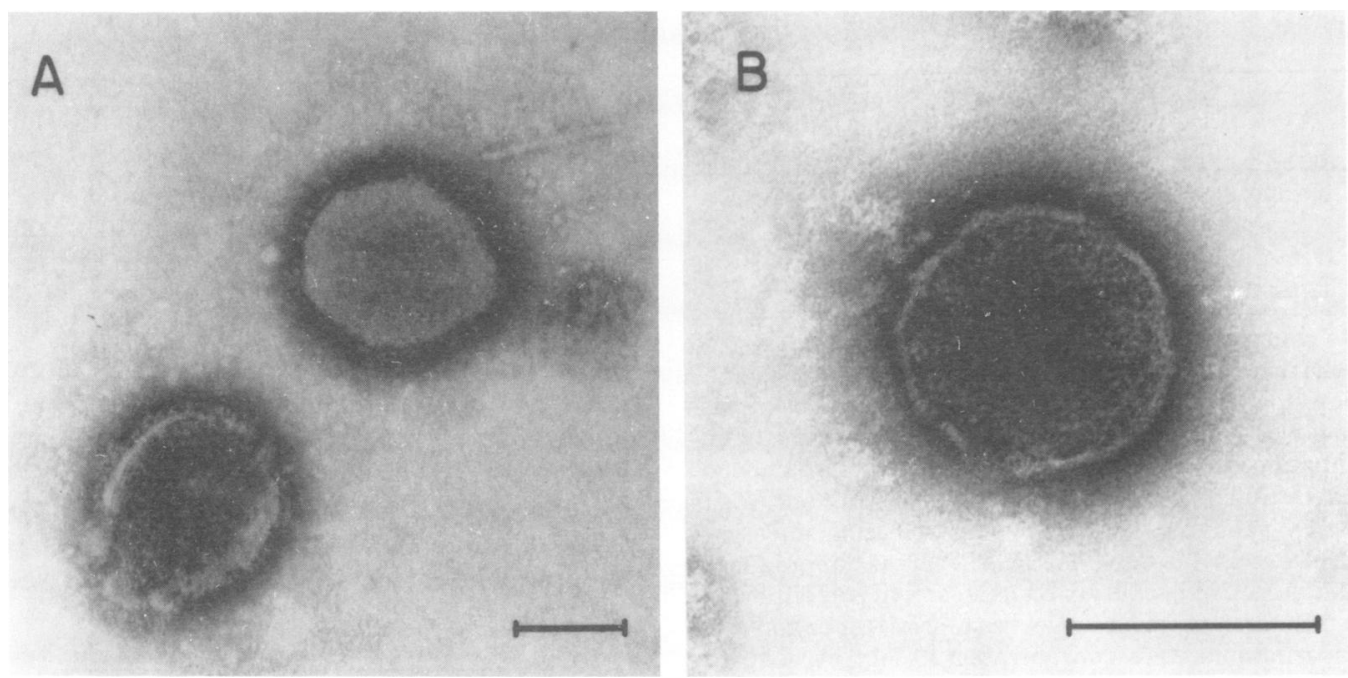

Fig. 2. Electron microscopy of particles of standard and defective virions. Virions were purifiecl by density gradient centrifugation, placed on carbon-coated copper grids and negatively stained with phosphotungstanate (9). (A) Standard virions from SWR4/M-MuLV. (B) Defective virions from SWR4. Bar = $100 \mathrm{~nm}$.

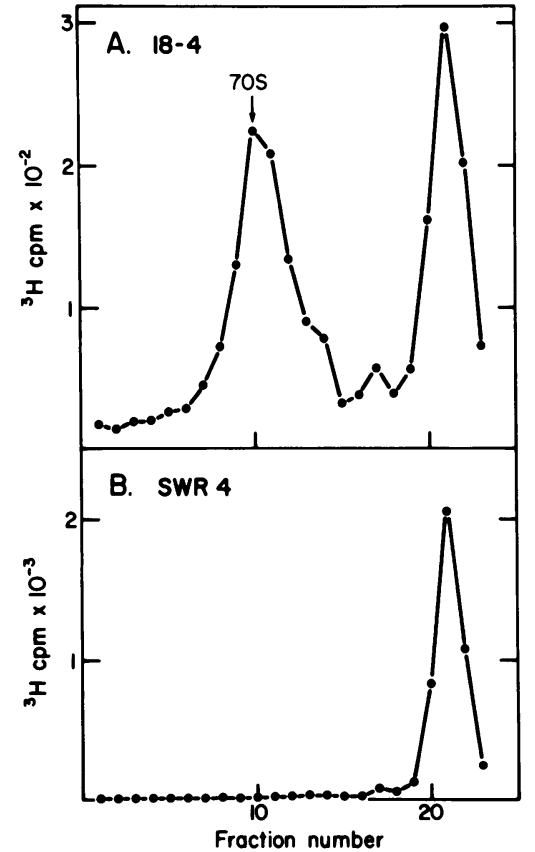

Fig. 3. Sucrose gradient centrifugation analysis of RNA from SWR4 and 18-4. [ ${ }^{3}$ H] uridine-labeled virions were prepared, and RNA was extracted, purified, and analyzed as described in Materials and Methods.

the enzyme of the defective virions and that of infectious virions (Fig. 4).

The major structural protein of standard and defective virions was analyzed by labeling deter-
TABLE 5. Exogenous and endogenous reverse transcriptase assays of standard and defective particles $^{a}$

\begin{tabular}{lccc}
\hline $\begin{array}{c}\text { Particles de- } \\
\text { rived from: }\end{array}$ & $\begin{array}{c}\text { Exogenous } \\
\text { reverse tran- } \\
\text { scriptase } \\
(\text { cpm } \times \\
\left.10^{-5}\right)\end{array}$ & $\begin{array}{c}\text { Endogenous } \\
\text { reverse tran- } \\
\text { scriptase } \\
(\text { cpm } \times \\
\left.10^{-3}\right)\end{array}$ & $\begin{array}{c}\text { Ratio of } \\
\text { endoge- } \\
\text { nous to } \\
\text { exogenous } \\
\text { relative to } \\
\text { M-MuLV }\end{array}$ \\
\hline $\begin{array}{cccc}\text { NIH/3T3 } \\
\text { SWR4/M- } \\
\text { MuLV }\end{array}$ & $5.0 \pm 0.8$ & $9.5 \pm 0.6$ & 1.0 \\
SWR4 & $6.0 \pm 2.8$ & $14.7 \pm 1.9$ & 1.29 \\
\hline
\end{tabular}

${ }^{a}$ Exogenous and endogenous reverse transcriptase assays were performed as described in Materials and Methods. In a separate experiment, the ratio of endogenous to exogenous reverse transcriptase assay for SWR4 particles relative to $\mathrm{M}-\mathrm{MuLV}$ was 0.1 .

${ }^{b} \mathrm{~A}$ cell line releasing standard M-MuLV.

gent-disrupted virions with ${ }^{125} \mathrm{I}$. These preparations were then immunoprecipitated with sera specific for M-MuLV p30 protein and glycoprotein (16) and analyzed by polyacrylamide gel electrophoresis (Fig. 5). The normal producer contained the expected p30 (lane A1) and gp70 (lane B1). The defective producer contained a major structural protein that migrated with an apparent molecular weight of 28,000 (lane A3). A p28 has also been detected in particles from two other A-MuLV-transformed NIH/Swiss defective producer cell lines (242; TB8-5, see below). Although we could detect no glycoprotein on the defective virions, the detection level for this protein is so poor that it may not be truly 
absent. Furthermore, there could be a glycoprotein present that was not precipitated by the antiserum used here. The superinfectability of SWR4, BR48, and 242 (Table 1), however, argues that there is little ecotropic glycoprotein present on the surface of the defective producer cells. The lack of glycoprotein in the defective virus is consistent with the absence of spikes when particles were examined by electron microscopy.

One possible origin of p28 could be processing of the M-MuLV gag polyprotein to generate p28 rather than p30. To determine if the defective producers were intrinsically able to synthesize p30 from the M-MuLV gag polyprotein, the virion proteins from SWR4/M-MuLV were analyzed. A mixture of p28 and p30 was discernable (Fig. 5, lane A2), implying that the defective producers can process the M-MuLV polyprotein normally.

Origin of defective particles. The genetic information coding for the defective virions might originate in the Abelson genome, in an altered helper virus, or in an endogenous virus. The Abelson virus genome is an unlikely source of the information for the defective virions because it codes for a protein, P120, that lacks most of the antigenicity of p30, does not give rise to detectable p30-like cleavage products, and lacks determinants of reverse transcriptase (35, 20). Furthermore, heteroduplex analysis has demonstrated that the regions of A-MuLV homologous to $\mathrm{M}-\mathrm{MuLV}$ are of insufficient size to code for all of p30 and reverse transcriptase (Shields et al., unpublished data).

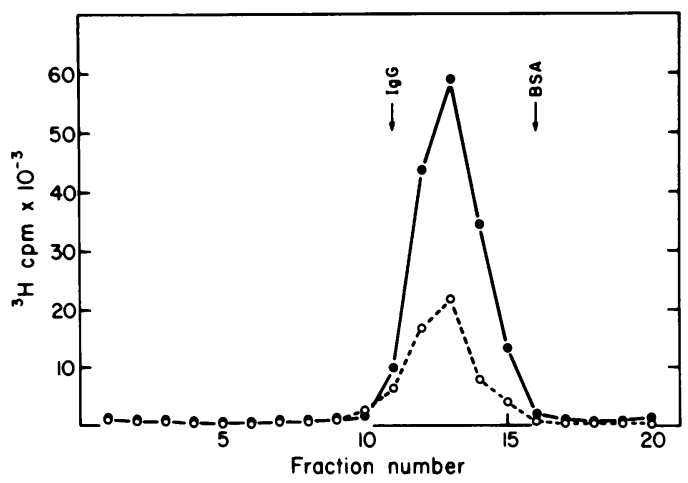

Fig. 4. Glycerol gradient centrifugation of reverse transcriptase from a defective producer, TB8-5, and a normal producer, TB11. Disrupted virions were sedimented on a 5 to $20 \%$ glycerol gradient, and the presence of the enzyme was quantitated by using the exogenous reverse transcriptase assay as described in Materials and Methods (34). ${ }^{125}$ I-labeled bovine serum albumin and fluoresceinated goat immunoglobulin $G$ were centrifuged in a parallel gradient as markers. Symbols: (O) TB11; (O) TB8-5.

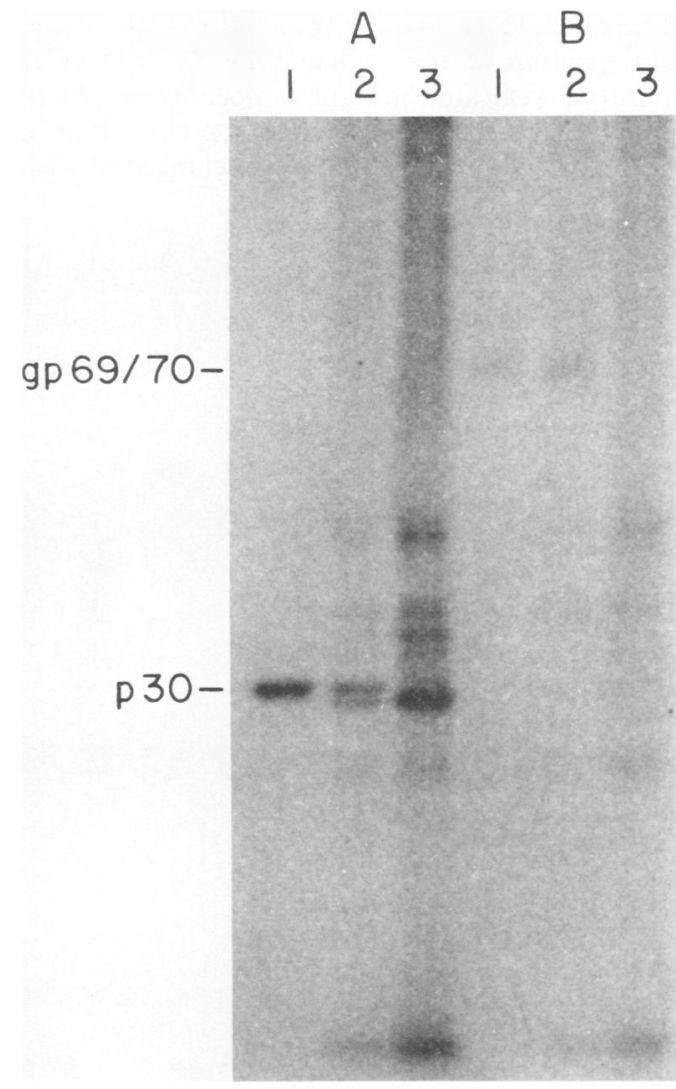

Fig. 5. Analysis of proteins contained in virions. Immunoprecipitates of ${ }^{125}$ I-labeled virions were analyzed by polyacrylamide gels as described in Materials and Methods. (A) Antiserum against p30; (B) antiserum against glycoprotein. Virion samples were derived from cell lines: (1) 18-4; (2) $S W R-4 / M-M u L V$; (3) SWR4.

Possible sources for the p28 were M-MuLV and the only known SWR/J endogenous virus (32). To compare the defective virion $\mathrm{p} 28$ with the major structural proteins of these viruses, virions were purified from SWR4 cells, 18-4 cells, and from SC-1 cells infected with the SWR/J virus. After disruption of the virions, the proteins were iodinated, immunoprecipitated with a serum specific for $\mathrm{p} 30$, and displayed by electrophoresis through an SDS-polyacrylamide gel. The bands containing the major structural protein were identified by autoradiography and excised from the dried gel. After rehydration, the gels slices were placed on a new gel and mixed with unlabeled M-MuLV p30, and the proteins were compared by partial proteolytic cleavage by the method of Cleveland et al. (4). Coomassie blue staining of the gel provided an internal standard with which to compare the autoradiogram and demonstrated that equal digestion 
occurred in all samples (Fig. 6). The major structural protein of the endogenous $\mathrm{SWR} / \mathrm{J}$ virus migrated with an apparent molecular weight of 27,000 (this difference in migration is evident in Fig. 6 when the autoradiogram is compared with the Coomassie blue stain). Analysis of digests by papain, pronase, and $S$. aureus protease demonstrated the marked similarity of p28 to the p30 of M-MuLV and the p27 of the SWR/J endogenous virus. There are, however, minor
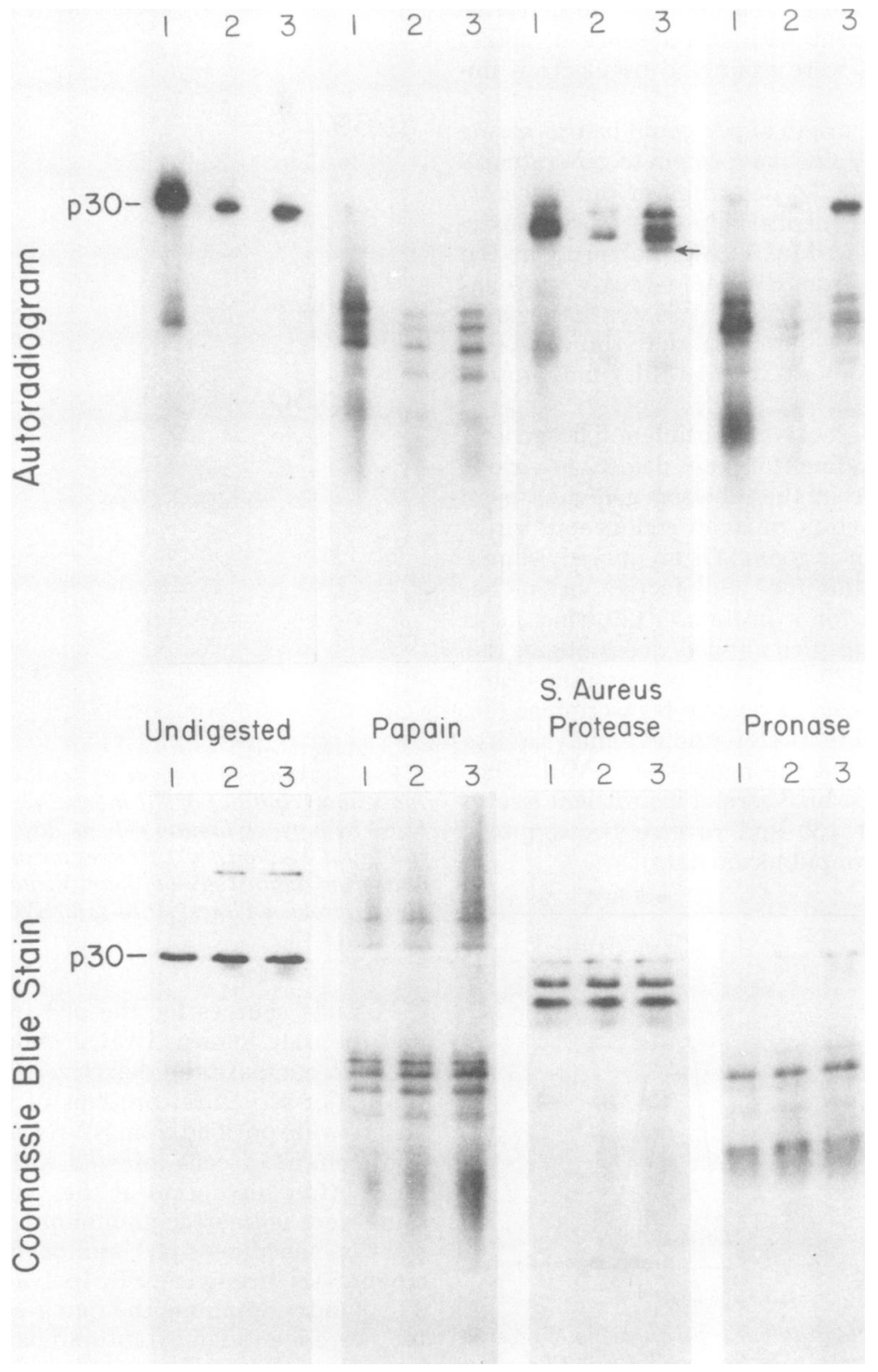

Fig. 6. Comparison of virion proteins by partial proteolytic cleavage. Purified virus was iodinated, and the major structural protein was purified and analyzed by partial digestion with the indicated protease during electrophoresis through a polyacrylamide gel (see Materials and Methods). Before digestion, each preparation of iodinated protein was mixed with unlabeled $M-M u L V$ p30. The autoradiogram displays the digests of the major structural proteins from: (1) 18-4, a normal lymphoid producer; (2) SWR4, a lymphoid defective producer; (3) an SC-1 cell line releasing the $S W R / J$ endogenous virus. The arrow indicates the difference in peptide patterns between the SWR/J endogenous virus and the other viruses. The Coomassie blue stain demonstrates the cleavage pattern of unlabeled M-MuLV p30. 


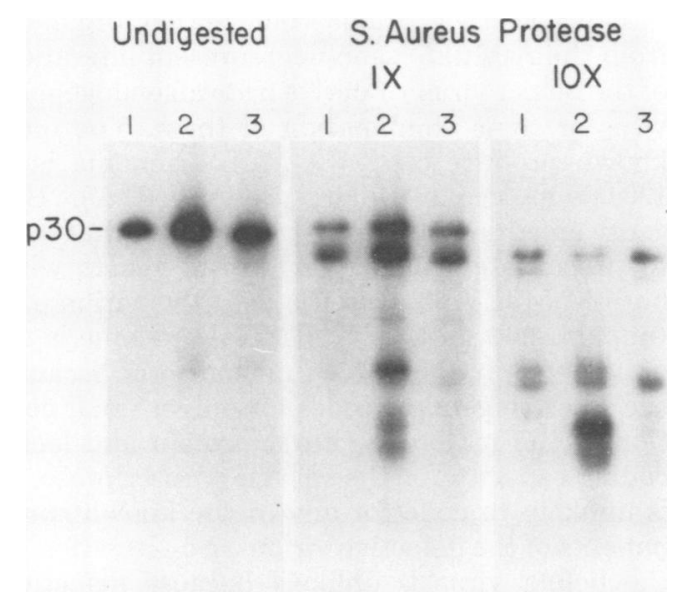

Fig. 7. Analysis of defective virions using $M$ MuLV-TB. Analysis was done as described in the legend to Fig. 6 and Materials and Methods, except that the samples indicated by $1 X$ were digested with a solution containing $100 \mu \mathrm{g}$ of $S$. aureus protease per $\mathrm{ml}$ and those indicated by $10 \mathrm{X}$ employed $1 \mathrm{mg}$ of $S$. aureus protease per $\mathrm{ml}$. The autoradiogram displays the digests of: (1) p30 from SWR4/M-MuLV, a clone which releases standard $M-M u L V$; (2) p30 from $T B 11$, a lymphoid producer releasing M-MuLV-TB; (3) p28 from TB8-5, a defective lymphoid producer.

differences between them, especially one band present in the SWR/J virus cleaved with $S$. aureus protease that was absent in the digests of the other two (arrow, Fig. 6; the lack of this peptide in the SWR4 p28 is more evident in the data presented in Fig. 7). Furthermore, many of the cleavage products of p28 migrated somewhat faster than those of M-MuLV p30, presumably reflecting the smaller size of the original protein.

The similarity of the digestion products from M-MuLV p30 and the defective particle p28 and the similar sedimentation of reverse transcriptase from the two virion preparations suggested that a possible origin of the defective virions could be through an alteration of the helper virus. When $\mathrm{M}-\mathrm{MuLV}$ virus infects fibroblasts it mutates at a rapid rate but produces a variety of defects, none of which include a smaller p30 (26). By contrast, the particles produced by the defective lymphoid producers are homogeneous in phenotype to the extent that all contain reverse transcriptase and lack infectivity in the $\mathrm{XC}$ and focus assays, and three have $\mathrm{p} 28$. The lymphoid cells could, however, either cause or select for a particular defect within the helper virus. This was tested by using as a helper another strain of M-MuLV (M-MuLV-TB) that can be distinguished from our standard M-MuLV and studying the resulting defective virions for changes in the major structural protein. Although this strain of virus contains a major structural protein of molecular weight 30,000 , the cleavage pattern of its p30 is different from that of our standard M-MuLV. Therefore, a stock of Abelson virus was produced with M-MuLV-TB helper, and this was used to derive a series of lymphoid clones from an NIH/Swiss mouse. Again a number of normal and defective producers was isolated and the defective virions of the tested cell line were shown to contain p28. When the proteins were compared by digestion with $S$. aureus protease (Fig. 7), a characteristic peptide difference was visible between the p30 of the lymphoid producer releasing standard $\mathbf{M}$ MuLV (lanes 1) and M-MuLV-TB (lanes 2). The p28 of the defective producer derived from the stock containing M-MuLV-TB appeared unchanged and similar to that of M-MuLV (lanes 3 ), however, suggesting that p28 is not derived from the helper virus. It is also evident from the 10X digests (Fig. 7) that M-MuLV and MMuLV-TB contain an extra band not present in p28.

\section{DISCUSSION}

Lymphoid cells transformed by A-MuLV have very different properties from A-MuLV-transformed fibroblasts. Lymphoid lines can be divided into three classes: producers, releasing infectious virus; nonproducers; and defective producers, releasing particulate reverse transcriptase but no infectious virus. The defective producers are the predominant phenotype isolated in each of the mouse strains tested. Clones of fibroblasts transformed with A-MuLV(MMuLV) were predominantly producers or nonproducers. In the series of transformed fibroblasts described here, only one clone released reverse transcriptase-containing particles that were not infectious in the XC and focus assays. It is probable that this clone is the result of a spontaneous mutation of M-MuLV, an event that occurs frequently in the helper virus (26). Because the level of reverse transcriptase is quite low in the lymphoid defective producers, it is possible that nonproducer fibroblasts may also release these particles but at a level not detectable in our assay.

The lymphoid defective producers may all have initially contained a competent helper virus genome because analysis of lymphoid clones before they were fully adapted to liquid medium showed that many produce infectious virus, although often at low titers. Furthermore, the inability of some helper viruses to make AMuLV competent to transform lymphoid cellsa behavior that does not correlate with helper 
virus tropism-suggests that the helper may play an active role in the early intracellular stages of A-MuLV lymphoid cell transformation $(22,24)$. Which helper virus function is needed and why oncogenicity of the helper correlates with lymphoid cell transformation but not fibroblast transformation are unanswered questions.

As lymphoid transformants grow, many cease to release infectious virus but continue to release defective virions. We have previously shown that A-MuLV-transformed lymphoid cells infected with helper virus may cease virus production as they are passaged $(22,35)$. This does not appear to be solely due to selection, because repeatedly cloned cell lines have been found to cease virus production. Lymphoid cells appear able to regulate helper virus gene expression because when A-MuLV nonproducer lymphoid cells are superinfected with a helper of low oncogenicity, they cease releasing virus after a few days. Even some A-MuLV-transformed lymphoid cells producing a helper virus of high oncogenicity have been found to cease virus production when carried in culture for several months. Cell lines derived from tumors induced by the in vivo inoculation of Friend MuLV complex into certain mouse strains also ceased to release infectious virus as the cells were passaged in vitro (7). By contrast, fibroblasts seem to stably release virus once a productive infection is established even with a helper of low oncogenicity.

The defective particles released by the lymphoid cells were found to have the density of normal virions and to contain reverse transcriptase of normal size. However, no 70S RNA was found as determined by analysis of $\left[{ }^{3} \mathrm{H}\right]$ uridine-labeled virions and by the endogenous reverse transcriptase assay. The low level of activity noted in the endogenous assays probably reflects transcription of small RNA packaged in the virions. It has been previously shown that virions lacking 70S RNA are produced after treatment of cells with actinomycin $\mathrm{D}$, and they also contain lowmolecular-weight RNA $(13,15)$. It is possible, though, that these analyses could be misleading if there were a relative overabundance of reverse transcriptase activity in the virions.

The defective virion's major structural protein migrates with an apparent molecular weight of 28,000 . The superinfectability of the defective producers suggests that the cells lack ecotropic glycoprotein and the virions are without spikes when viewed with the electron microscope; virions lacking glycoprotein have been demonstrated previously (5). We cannot be entirely certain, however, that the particles lack glycoprotein because a glycoprotein that does not react with antiserum made against $\mathrm{M}-\mathrm{MuLV}$ gp70 could be present.
The defective virions could either originate from the A-MuLV genome, represent alteration of the helper virus, or derive from an endogenous virus or some combination of these. The only known product of the A-MuLV genome is a 120,000 -molecular-weight protein (P120). Because an antiserum has been produced that fails to precipitate A-MuLV P120 but reacts with both M-MuLV p30 and the defective virion p28 (unpublished data), the A-MuLV genome is an unlikely source for p28. Furthermore, because the Abelson genome codes for only a small portion of the major structural protein and lacks coding capacity for the reverse transcriptase, it is unlikely to code for any of the known components of the defective virions. An alteration of the helper virus is unlikely because defective virions in lymphoid cells induced with another strain of M-MuLV as helper (M-MuLV-TB), contained p28 with an unaltered cleavage pattern and one that was different from that of the p30 of M-MuLV-TB. A modification of the helper virus could have occurred, however, that changed p30 to p28 and obliterated the helper's characteristic peptide.

The defective virus could in principle derive from a defective virus carried in our viral stocks. Although the generation of defective producers has been observed with several different wellcloned stocks of virus, we cannot rigorously exclude this explanation. We feel that the most likely origin of the defective genome, however, is from an endogenous mouse virus. When we tested the only known endogenous virus of the SWR/J mouse we found that its major structural protein had a size different from that of p28. Although the cleavage patterns of the endogenous virus $\mathrm{p} 27$ and defective virion $\mathrm{p} 28$ were similar, there were minor differences. Analysis of the DNA from many strains of laboratory mice, however, has demonstrated the existence of multiple genes with homology to M-MuLV (31). The existence of another undetected endogenous virus is quite possible because it appears to be without infectivity and might only express itself in early lymphoid cells. In this regard it is important to remember that endogenous viral genes are known to be expressed in various tissues including B-lymphoid cells $(1,14$, 30 ). We were unable to test uninfected lymphoid cells of the same differentiation state as AMuLV-transformed cells because they could not be propagated in culture.

Lymphoid cell transformation with A-MuLV is significantly different from the transformation of fibroblasts. This suggests that lymphoid cells express virus in unique ways. The ability of lymphoid cells to cease the production of helper viruses and the release of defective virions by 
such cells may be reflections of their differentiated state.

\section{ACKNOWLEDGMENTS}

We thank Owen Witte for helpful discussions during the course of this work.

This work was supported by grant VC-4J from the American Cancer Society and grants CA-24220 and CA-14051 from the National Cancer Institute. N.R. is a Research Scholar of the American Cancer Society, Massachusetts Division. D.B. is a Research Professor of the American Cancer Society.

\section{LITERATURE CITED}

1. Aaronson, S. A., and J. R. Stephenson. 1974. Widespread natural occurrence of high titers of neutralizing antibodies to a specific class of endogenous mouse typeC virus. Proc. Natl. Acad. Sci. U.S.A. 71:1957-1961.

2. Bassin, R. H., N. Tuttle, and P. J. Fischinger. 1971. Rapid cell culture assay technique for murine leukaemia viruses. Nature (London) 229:564-566.

3. Besmer, P., D. Smotkin, W. Haseltine, H. Fan, A. T. Wilson, M. Paskind, R. Weinberg, and D. Baltimore. 1974. Mechanism of induction of RNA tumor viruses by halogenated pyrimidines. Cold Spring Harbor Symp. Quant. Biol. 39:1103-1107.

4. Cleveland, D. W., S. G. Fischer, M. W. Kirchner, and U. K. Laemmli. 1977. Peptide mapping by limited proteolysis in sodium dodecyl sulfate and analysis by gel electrophoresis. J. Biol. Chem. 252:1102-1106.

5. Eisenman, R. N., and V. M. Vogt. 1978. The biosynthesis of oncovirus proteins. Biochim. Biophys. Acta 473:187-239.

6. Fan, H., and M. Paskind. 1974. Measurement of the sequence complexity of cloned Moloney murine leukemia virus 60 to $70 S$ RNA: evidence for a haploid genome. J. Virol. 14:421-429.

7. Freedman, H. A., and F. Lilly. 1975. Properties of cell lines derived from tumors induced by Friend virus in BALB/c and BALB/c-H-2 ${ }^{b}$ mice. J. Exp. Med. 142: 212-223.

8. Greenwood, F. C., W. M. Hunter, and J. S. Glover. 1963. The preparation of ${ }^{131}$ I-labeled human growth hormone of high specific radioactivity. Biochem. J. 89: 114-123.

9. Hayat, M. A. 1972. Basic electron microscopic techniques. Van Nostrand Reinhold Co., New York.

10. Kerr, I. M., U. Olshevsky, H. F. Lodish, and D. Baltimore. 1976. Translation of murine leukemia virus RNA in cell-free systems from animal cells. J. Virol. 18: 627-635.

11. Kessler, S. W. 1975. Rapid isolation of antigens from cells with a staphylococcal protein A-antibody adsorbent: parameters of the interaction of antibody-antigen complexes with protein A. J. Immunol. 115:1617-1624.

12. Laemmli, U. K. 1970. Cleavage of structural proteins during the assembly of the head of bacteriophage T4. Nature (London) 227:680-685.

13. Levin, J. G., P. M. Grimley, J. M. Ramseur, and I. K. Berezesky. 1974. Deficiency of 60 to $70 S$ RNA in murine leukemia virus particles assembled in cells treated with actinomycin D. J. Virol. 14:152-161.

14. Moroni, C., and G. Schumann. 1975. Lipopolysaccharide induces $C$-type virus in short term culture of BALB/c spleen, cells. Nature (London) 254:60-61.

15. Paskind, M., R. Weinberg, and D. Baltimore. 1975. Dependence of Moloney murine leukemia virus production on cell growth. Virology $67: 242-248$.

16. Philipson, L., P. Andersson, U. Olshevsky, R. Weinberg, D. Baltimore, and R. Gestland. 1978. Translation of MuLV and MSV RNAs in nuclease treated reticulocyte extracts: enhancement of the gag-pol polypeptide with yeast suppressor tRNA. Cell 13:189-199.

17. Phillips, D. R., and M. Morrison. 1971. Exposed protein on the intact human erythrocyte. Biochemistry 10: 1766-1771.

18. Pratt, D. M., J. Stromingèr, R. Parkman, D. Kaplan, J. Schwaber, N. Rosenberg, and C. D. Scher. 1977. Abelson virus-transformed lymphocytes: null cells that modulate H-2. Cell 12:683-690.

19. Premkumar, E. M., M. Potter, P. A. Singer, and M. D. Sklar. 1975. Synthesis, surface deposition, and secretion of immunoglobulins by Abelson virus-transformed lymphosarcoma cell lines. Cell 6:149-159.

20. Reynolds, F. H., T. L. Sacks, D. N. Deobagkar, and J. R. Stephenson. 1978. Cells nonproductively transformed by Abelson murine leukemia virus express a high molecular weight polyprotein containing structural and nonstructural components. Proc. Natl. Acad. Sci. U.S.A. 75:3974-3978.

21. Rosenberg, N., and D. Baltimore. 1976. A quantitative assay for transformation of bone marrow cells by Abelson murine leukemia virus. J. Exp. Med. 143:1453-1463.

22. Rosenberg, N., and D. Baltimore. 1978. The effect of helper virus on Abelson virus-induced transformation of lymphoid cells. J. Exp. Med. 147:1126-1141.

23. Rose, W. P., W. E. Pugh, and J. W. Hartley. 1970. Plaque assay techniques for murine leukemia viruses. Virology 42:1136-1139.

24. Scher, C. D. 1978. Effect of pseudotypes on Abelson virus and Kirsten sarcoma virus induced leukemia. J. Exp. Med. 147:1044-1053.

25. Scher, C. D., and R. Siegler. 1975. Direct transformation of 3T3 cells by Abelson murine leukemia virus. Nature (London) 253:729-731.

26. Shields, A., O. N. Witte, E. Rothenberg, and D. Baltimore. 1978. High frequency of aberrant expression of Moloney murine leukemia virus in clonal infections. Cell 14:601-609.

27. Siden, E. J., D. Baltimore, D. Clark, and N. Rosenberg. 1979. Immunoglobulin synthesis by lymphoid cells transformed in vitro by Abelson murine leukemia virus. Cell 16:289-396.

28. Silverstone, A. E., N. Rosenberg, V. L. Sato, M. P. Scheid, E. A. Boyse, and D. Baltimore. 1978. Correlating terminal deoxynucleotidyl transferase and cellsurface markers in the pathway of lymphocyte ontogeny, p. 433-453. In B. Clarkson, P. A. Marks, and J. E. Till (ed.), Differentiation of normal and neoplastic hematopoietic cells. Cold Spring Harbor Laboratory, Cold Spring Harbor, New York.

29. Sklar, M. D., E. M. Shevach, I. Green, and M. Potter. 1975. Transplantation and preliminary characterization of lymphocyte surface markers of Abelson virus-induced lymphomas. Nature (London) 253:550-552.

30. Staber, F. G., E. Schlafli, and C. Moroni. 1978. Expression of endogenous C-type viral antigen on normal mouse haemopoietic stem cells. Nature (London) 275: 669-671.

31. Steffen, D., and R. A. Weinberg. 1978. The integrated genome of murine leukemia virus. Cell 15:1003-1010.

32. Stephenson, J. R., and S. A. Aaronson. 1976. Induction of an endogenous B-tropic type C RNA virus from SWR/J mouse embryo cells in tissue culture. Virology 70:352-359.

33. Weimann, B. J. 1976. Induction of immunoglobulin synthesis in Abelson murine leukemia virus-transformed mouse lymphoma cells in culture. Cold Spring Harbor Symp. Quant. Biol. 41:163-164.

34. Witte, O. N., and D. Baltimore. 1978. Relationship of retrovirus polyprotein cleavages to virion maturation studied with temperature-sensitive murine leukemia virus mutants. J. Virol. 26:750-761.

35. Witte, O. N., N. Rosenberg, M. Paskind, A. Shields, and D. Baltimore. 1978. Identification of an Abelson murine leukemia virus-encoded protein present in transformed fibroblast and lymphoid cells. Proc. Natl. Acad. Sci. U.S.A. 75:2488-2492. 